


\section{Physiotherapy in respiratory disease}

\section{Educational aims}

1 To motivate the interest of chest physicians in physiotherapy.

1 To provide a conceptual framework of physiotherapy in a variety of respiratory conditions.

1 To provide details about efficacy of physiotherapy in respiratory conditions.

\section{Summary}

Physiotherapy is relevant to the treatment of patients with acute and chronic lung disease, but it is also effective in patients with advanced neuromuscular disorders, in patients admitted for major surgery and patients with critical illness in the intensive care unit (ICU). Physiotherapy contributes to the assessment and treatment of various aspects of respiratory disorders, such as airflow obstruction, atelectasis, mucus retention, respiratory and peripheral muscle weakness, impaired exercise performance, dyspnoea, and quality of life. This overview discusses the contribution of physiotherapy in three conditions related to respiratory disease: deconditioning; dyspnoea and respiratory pump dysfunction; and impaired airway clearance and lung inflation.

\section{Deconditioning: exercise training and peripheral muscle training}

Impaired exercise tolerance is a common finding in patients with respiratory diseases such as chronic obstructive pulmonary disease (COPD), asthma, cystic fibrosis, pulmonary hypertension, interstitial lung disease and other respiratory conditions associated with major deconditioning (i.e. critically ill patients in the ICU). Reduced levels of physical activity are commonly observed in patients with chronic and acute-on-chronic diseases, including COPD [1] or acute lung injury [2], and are related to an increased risk of hospital readmission and mortality in this population [3]. Reduced exercise capacity shows only a weak association with impairment of lung function. Other factors, such as peripheral and respiratory muscle weakness, and deconditioning are now recognised as important contributors to reduced exercise tolerance $[2,4]$.

Randomised controlled studies on the efficacy of pulmonary rehabilitation, including exercise training, have reported significant improvements in maximal exercise capacity, walking distance, and quality of life and symptoms [4]. Although these programmes are comprehensive, most authors consider moderate-to-high endurance exercise training (cycling or walking) as a mandatory part of any pulmonary rehabilitation programme.

For patients with more advanced disease, it is essential to reduce the impact on the
The ERS designates this

educational activity for a maximum of 1 CME credit. For

information on how to earn

CME credits, see page 106.

\section{R. Gosselink}

Respiratory Rehabilitation and
Respiratory Division
University Hospitals Leuven
Faculty of Kinesiology and
Rehabilitation Sciences
Katholieke Universiteit Leuven
B-3000
Belgium
Fax: 32 16329196
E-mail:
Rik.Gosselink@faber.kuleuven.be

This material was based in part on work supported by Fonds voor Wetenschappelijk OnderzoekVlaanderen Grant G 0523.06. 


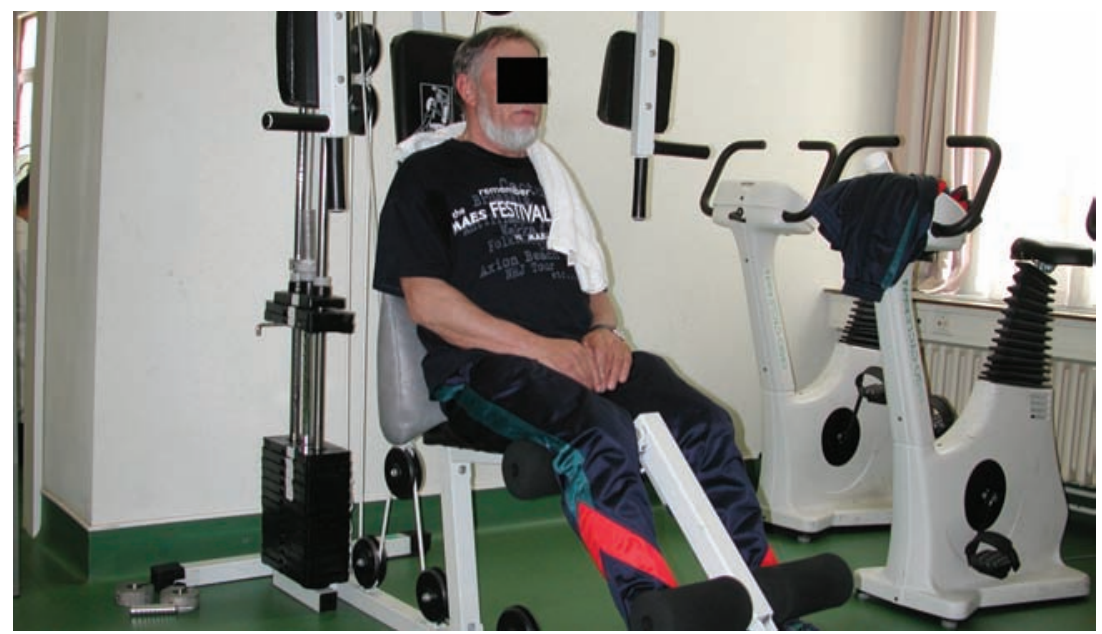

Figure 1

Resistance muscle training for lower limbs in a patient with COPD.

Figure 2

Device for active and passive cycling in a bed-ridden patient in the ICU (Motomed Letto; RECK, Betzenweiler, Germany).

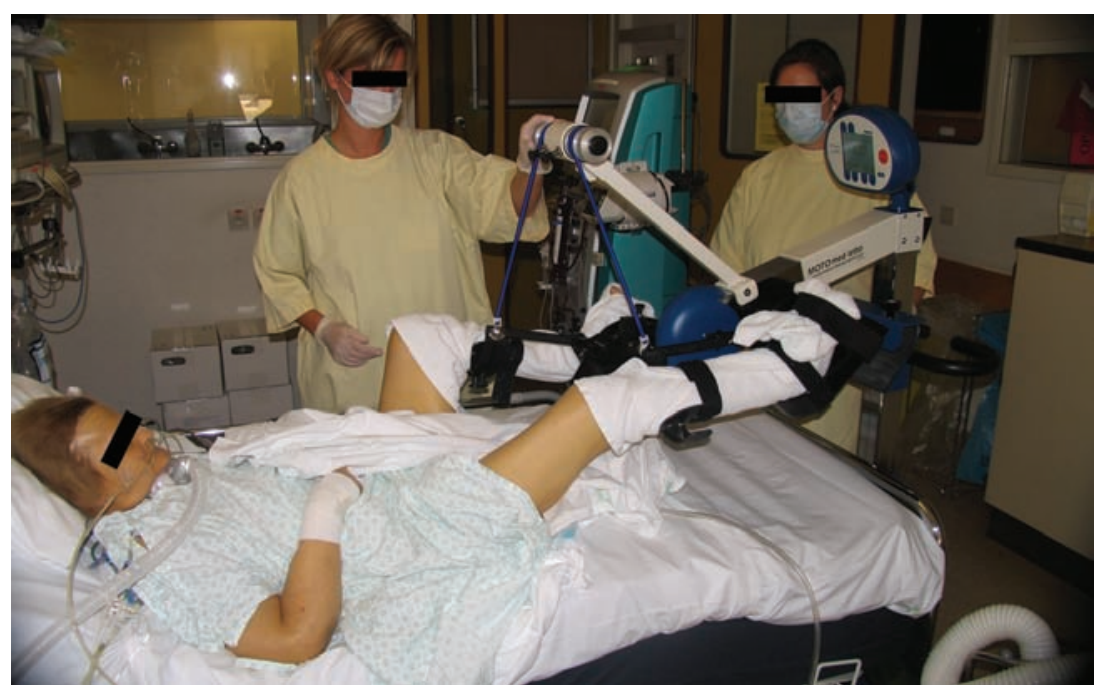

muscle fibre atrophy and protein loss [9]. In addition, electrical stimulation of the quadriceps (figure 3), with active limb mobilisation, enhances muscle strength and decreases the number of days needed to transfer a patient from bed to chair [10]. Recent studies also underpin the need for exercise training after a period of critical illness to enhance functional capacity [11].

\section{Dyspnoea and respiratory pump dysfunction}

Dyspnoea is an important and debilitating symptom in patients with respiratory conditions. Several pathophysiological factors known to contribute to dyspnoea include: increased intrinsic mechanical loading of the inspiratory muscles, increased mechanical restriction of the chest wall, functional inspiratory muscle weakness, increased ventilatory demand related to capacity, gas exchange abnormalities, dynamic airway compression, and cardiovascular effects. The relief of dyspnoea is an important aim of the treatment of respiratory diseases. In addition to medication, oxygen therapy and exercise training, breathing techniques are also applied to alleviate symptoms and improve respiratory physiology.

"Breathing exercise" is an allembracing term for a range of exercises such as active expiration, slow-and-deep breathing, pursed-lips breathing, relaxation therapy, body positions such as forward leaning, inspiratory and expiratory muscle training, and diaphragmatic breathing. The aims of these exercises vary considerably and include the improvement of (regional) ventilation and gas exchange, reduction of dynamic hyperinflation, improvement of respiratory muscle function, decreasing dyspnoea, and improvement of exercise tolerance and quality of life [12].

\section{Breathing retraining to reduce dynamic hyperinflation of the ribcage}

The concept of decreasing dynamic hyperinflation of the ribcage is based on the assumption that this intervention will decrease the elastic work of breathing and allow the inspiratory muscles to work over a more advantageous part of their length-tension relationship. Several treatment strategies aim to reduce the hyperinflated chest wall. 


\section{Relaxation exercises}

The rationale for relaxation exercises arises from the observation that slowing down the respiratory rate will allow more time for expiration. In COPD patients, RENFOE [13] has previously shown that progressive relaxation results in an immediate decrease in heart rate, respiratory rate, and anxiety and dyspnoea scores when compared to a control group. However, only respiratory rate dropped significantly over time.

\section{Pursed-lips breathing}

Pursed-lips breathing aims to improve expiration both by active and prolonged expiration through half-opened lips, and by preventing airways collapse. Compared to spontaneous breathing, pursed-lips breathing reduces a patient's respiratory rate, hyperinflation, dyspnoea and arterial carbon dioxide pressure, and improves tidal volume and oxygen saturation under resting conditions [14, 15]. However, its application during treadmill exercise has not been shown to improve blood gases.

Recently, GARROD et al. [16] observed that pursed-lips breathing during a 6-minute walking test resulted in a lower respiratory rate after the walking test when compared to natural breathing during the walking test. Also during pursedlip breathing, BRESLIN [15] observed an increase in ribcage and accessory muscle recruitment during the entire breathing cycle, while the tension-time index of the diaphragmatic contraction decreased. These changes may have contributed to the decrease in dyspnoea sensation that was observed.

Some COPD patients use pursed-lips breathing instinctively, while other patients do not. Changes in minute ventilation and gas exchange are not significantly related to the patients who report subjective improvement of the sensation of dyspnoea. In fact, "symptom-benefit patients" have been shown to have a more marked increase of tidal volume and decrease-of-breathing frequency, while others have reported a reduced elastic recoil pressure [12].

In conclusion, pursed-lips breathing has been found to be effective in improving gas exchange, and reducing hyperinflation and dyspnoea. COPD patients who do not spontaneously adopt pursed-lips breathing show variable responses. Those patients with loss of elastic recoil pressure seem to benefit more from practicing this technique during exertion and episodes of dyspnoea.

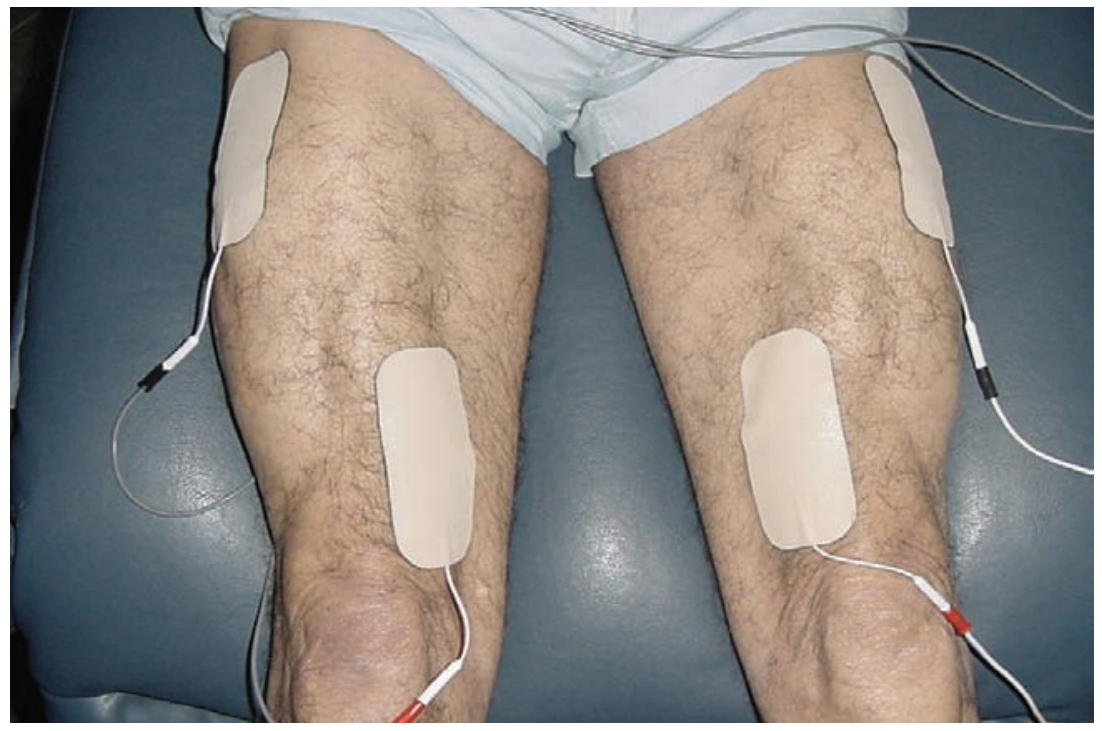

\section{Breathing retraining to improve respiratory muscle function}

Reduced endurance and strength of the inspiratory muscles are frequently observed in chronic lung disease and neuromuscular disorders, and contribute to dyspnoea, exercise limitation and, probably, to weaning failure. Improvement of respiratory muscle function is aimed at reducing the relative load on the muscles (the fraction of the actual pressure and the maximal pressure) and, hence, may contribute to reducing dyspnoea and to increasing sustained ventilatory capacity and, potentially, exercise capacity. Breathing retraining and body positions aim to improve the length-tension relationship or geometry of the respiratory muscles (in particular of the diaphragm), or increase strength and endurance of the inspiratory muscles.

\section{Contraction of the abdominal muscles during expiration}

Contraction of the abdominal muscles during expiration lengthens the diaphragm, allowing it to operate close to its optimal length and enhancing lung volume changes. In addition, active expiration will increase elastic recoil pressure of the diaphragm and the ribcage. The release of this pressure after relaxation of the expiratory muscles will assist the next inspiration. In patients with severe COPD, contraction of abdominal muscles becomes invariably linked to resting breathing. Active expiration increases transdiaphragmatic pressure and maximal inspiratory pressure. CASCIARI et al. [17] have previously observed a significant increase in maximum oxygen uptake during a cycle ergometry test after a period of additional breathing
Figure 3

Neuromuscular stimulation of the quadriceps femoris muscles. 


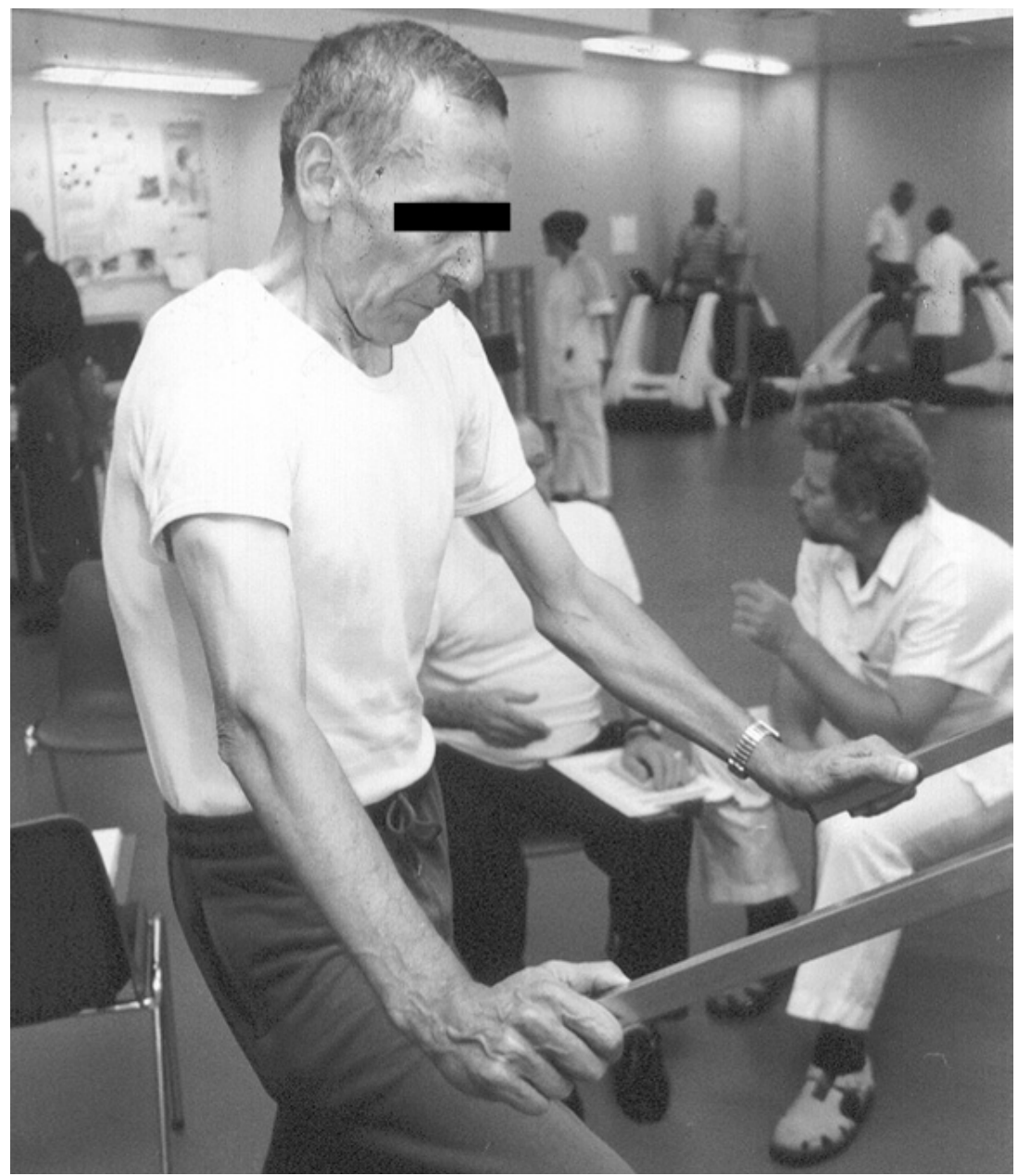

Figure 4

Forward leaning position allowing recruitment of accessory muscles and relief of dyspnoea. retraining with active expiration during a training programme on a treadmill when compared to the treadmill programme without breathing retraining. Although active expiration seems to improve inspiratory muscle function, and is commonly observed in resting breathing and during exercise in COPD patients, the significance of abdominal muscle activity remains poorly understood.

\section{Body position}

Relief of dyspnoea is often experienced by patients in different body positions. Forward leaning has been shown to be very effective in COPD [18], and is probably the most adopted body position by patients with lung disease. Forward leaning (figure 4) is associated with a significant reduction in electromyography activity of the scalenes and sternomastoid muscles, increase in transdiaphragmatic pressure, and significant improvement in thoraco-abdominal movements [18].

\section{Abdominal belt}

The "abdominal belt" was developed as an aid to support diaphragmatic function. Early studies were reported in patients with emphysema, but its use is only successful in patients with spinal cord injury in whom it improves vital capacity [19]. However, increases in expiratory flow and expiratory pressures during abdominal strapping were not consistently observed in these patients.

\section{Respiratory muscle training}

Respiratory muscles weakness has been associated with dyspnoea, impaired cough, exercise limitation and weaning failure in patients with respiratory conditions. Well-controlled inspiratory muscle resistance training (figure 5) improves inspiratory muscle function, resulting in an additional decrease in dyspnoea and nocturnal desaturation time, and, potentially, improvement of exercise capacity in COPD patients with inspiratory muscle weakness [20]. Training intensity should be $\geq 30 \%$ of the maximal inspiratory pressure for 30 minutes per day.

In tetraplegic patients, respiratory muscle resistance training has also been suggested to enhance inspiratory muscle function, pulmonary function and dyspnoea, although a recent systematic review could not confirm this [21]. In patients with neuromuscular disease (NMD), respiratory muscle dysfunction is more complex, and only patients who have $>25 \%$ of the predicted value of pulmonary function left are trainable.

Expiratory muscle function is often impaired in tetraplegia and multiple sclerosis. Expiratory muscle training has also been shown to be beneficial in the latter condition [22]. In the long term, the progressive nature of most NMDs affecting the primary function of the muscles probably impedes the beneficial effects of training.

Finally, respiratory muscle weakness is a frequent cause of weaning failure. Uncontrolled trials have suggested that inspiratory muscle training during the weaning period could facilitate the weaning process [23]. Biofeedback from the pattern of breathing to the patient can also enhance the weaning process of patients receiving long-term mechanical ventilation.

\section{Breathing retraining to optimise thoraco-abdominal movements}

Alterations of chest wall motion are common in patients with asthma and COPD. Several studies have described an increase in ribcage contribution to chest wall motion and/or asynchrony between ribcage and abdominal motion in these patients. Activity of accessory muscles is positively associated with the sensation of 
dyspnoea, whereas diaphragm activity is negatively related to dyspnoea sensation. Consequently, diaphragmatic breathing, or slowand-deep breathing, are commonly applied in physiotherapy practice in an attempt to correct abnormal chest wall motion, decrease work of breathing, accessory muscle activity and dyspnoea [12].

\section{Diaphragmatic breathing}

During diaphragmatic breathing, the patient is instructed to move the abdominal wall predominantly during inspiration and to reduce upper ribcage motion. All studies show that, during diaphragmatic breathing, COPD patients are voluntarily able to change their breathing pattern to more abdominal movement and less thoracic excursion. However, diaphragmatic breathing can be accompanied by increased asynchronous and paradoxical breathing movements, while no permanent changes of the breathing pattern are observed [12]. Although abdominal and thoracic movement have been reported to clearly change, no changes in ventilation distribution were observed. In addition, dyspnoea worsened during diaphragmatic breathing, while an increased work of breathing, enhanced oxygen cost of breathing and reduced mechanical efficiency of breathing have been found in patients with severe COPD [24]. In conclusion, there is no evidence from controlled studies to support the use of diaphragmatic breathing in COPD patients.

\section{Slow-and-deep breathing}

Since, for a given minute ventilation, alveolar ventilation improves when breathing at a slower rate and higher tidal volume, this type of breathing is encouraged for patients with impaired alveolar ventilation. Several authors have reported a significant drop in respiratory frequency, and a significant rise in tidal volume and arterial oxygen tension during imposed low-frequency breathing at rest in patients with COPD (see Pursed-lips breathing). Slow-and-deep breathing retraining as part of pulmonary rehabilitation during exercise training may result in more efficient breathing during exercise and, hence, reduce the ventilatory demand and dyspnoea [12]. In summary, slow-and-deep breathing improves breathing efficiency and oxygen saturation at rest. A similar tendency has been observed during exercise, but needs further research.

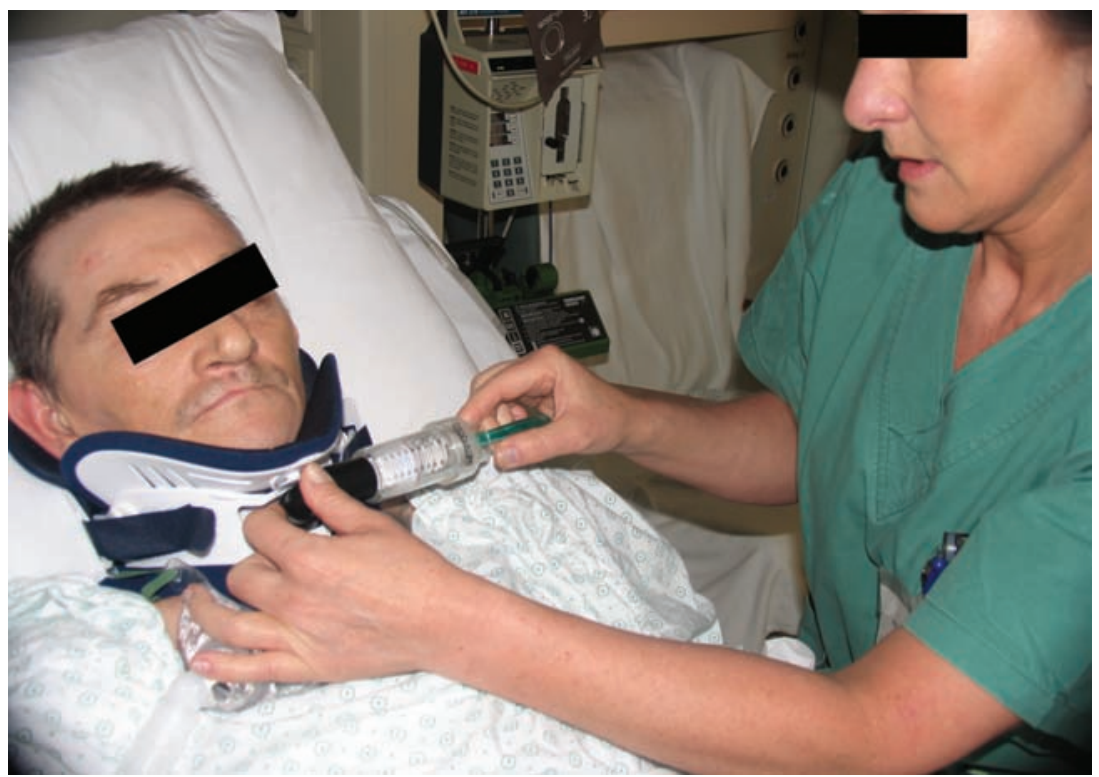

\section{Impaired airway clearance and lung inflation}

Hypersecretion and impaired mucociliary transport are important pathophysiological features of obstructive lung diseases, including cystic fibrosis, chronic bronchitis and NMD, as well as in patients with acute lung disease (i.e. atelectasis and pneumonia). Hypersecretion is associated with an increased rate of decline of pulmonary function, and excess mortality and morbidity. Although a cause-effect relationship has not been proven in these conditions, improvement of airway clearance is considered an important aim of treatment of these patients. Pharmaceutical interventions and physiotherapy are effective at enhancing mucus transport by improving the rheological properties of the mucus layer, stimulating ciliary action or utilising compensatory physical mechanisms, such as gravity, two-phase gas-liquid interaction, vibration, oscillation or airway compression.

A meta-analysis in patients with cystic fibrosis [25] concluded that the combined standard treatment of postural drainage, percussion and vibration resulted in significantly greater sputum expectoration when compared to no treatment. No differences were observed between standard treatment and other treatment modalities. A Cochrane library review in patients with COPD and bronchiectasis concluded that the combination of postural drainage, percussion and forced expiration improved airway clearance, but not pulmonary function [26]. Forced expiratory
Figure 5

Respiratory muscle resistive training with threshold loading in a patient weaning from mechanical ventilation. 
manoeuvres, huffing and coughing, are considered the cornerstone of airway clearance techniques, and, thus, an essential part of every combination of treatment modalities.

\section{Forced expiration techniques}

The concept of therapeutic forced expiratory manoeuvres is to enhance mucus transport due to the interaction and energy transfer between the high airflow velocity and the mucus layer (two-phase gas-liquid interaction). Huffing and coughing and, also, though to a lesser extent, ventilation at rest or during exercise induce higher airflow velocities that, equally effectively, stimulate mucus transport from central and intermediate lung zones [27]. However, in patients with airway instability (pulmonary emphysema), forced expiratory manoeuvres may result in airway collapse and impairment of mucus transport. Indeed, manual chest wall compression during forced expiration has been shown to decrease peak cough flow rate in patients with severe COPD [28]. In contrast, in NMD, reduced expiratory muscle strength limits effective huffing and coughing. Manual assistance with chest wall compression enhances peak cough flow rate in patients with NMD without scoliosis, but was not shown to be beneficial in patients with chest wall deformities [28]. In addition, deep inspiration increases maximum insufflation capacity and peak cough flow in patients with progressive NMD [28]. Mechanical insufflation and exsufflation, and manually assisted coughing are effective and safe to facilitate clearance of airway secretions [29]. Glossopharyngeal breathing has been shown to increase vital capacity and expiratory flow rates, and is a treatment option in patients with high spinal cord injury.
Figure 6

Breathing exercises with positive expiratory pressure mask in a patient with cystic fibrosis.

\section{Exercise}

During exercise, increased ventilation and release of mediators in the airways may be effective in enhancing mucus transport [30]. Indeed, increased mucus transport has been observed during exercise in healthy subjects and patients with chronic bronchitis [31], but it was less effective than conventional physiotherapy in patients with cystic fibrosis. During exercise combined with physiotherapy, significantly more sputum volume was expectorated than during physiotherapy alone [32].

\section{Postural drainage and body position}

During postural drainage, the major bronchi are positioned to allow gravitational forces to promote mucus transport to the central airways. Studies investigating the efficacy of postural drainage and using radio aerosol tracer assessment showed no additional improvement in mucus transport after postural drainage [33], but, in patients with bronchiectasis and excessive mucus production, postural drainage alone enhanced mucus transport and expectoration [34].

Body position has also been shown to affect oxygenation. This effect has not always been acknowledged in clinical care. In patients with unilateral lung disease, the lateral decubitus position with the unaffected side down, in general, improves oxygenation. In patients with acute respiratory distress syndrome, the prone position increases arterial oxygen pressure. Alterations in ventilation-perfusion inequality have been suggested as the main reason for improved oxygenation in these body positions.

\section{Percussion and vibration}

Manual or mechanical percussion and vibration are based on the assumption of transmission of oscillatory forces to the bronchi. Although such oscillations are observed during bronchoscopy in the central airways, it is believed that absorption of the forces by air and lung parenchyma prevents transmission to smaller and intermediate airways. This probably explains the lack of additional effects on mucus transport of adding chest percussion and vibration to breathing retraining, postural drainage and coughing [35]. Another explanation might be the frequency dependence of the effects of vibration and oscillation. However, clinical trials have not shown greater efficacy of high-frequency oscillation with a more optimal oscillation frequency when compared to standard physiotherapy in patients with chronic bronchitis and cystic fibrosis in a stable condition or hospitalised. 
5. Positive expiratory pressure mask breathing and Flutter breathing

Positive expiratory pressure mask breathing (figure 6) was introduced to prevent airway collapse and improve collateral ventilation, and, thus, to enhance mucus transport. Indeed, FALK et al. [36] showed that the addition of this technique to forced expiration or postural drainage increased mucus expectoration in cystic fibrosis. Other investigators were unable to show additional shortterm effects on mucus transport in cystic fibrosis or chronic bronchitis. However, it has been demonstrated that positive expiratory pressure therapy is superior to standard treatment in preserving pulmonary function in the long term [37].

Flutter breathing is the addition of a variable, oscillating expiratory pressure and airflow at the mouth to facilitate clearance of mucus. Although patients with cystic fibrosis have been observed to have a five-fold increase in expectorated mucus when compared to cough or postural drainage, others were unable to find differences in expectoration. Sputum rheology has been shown to be significantly altered during Flutter breathing, but this did not result in an increased sputum volume.

\section{Lung inflation and chest expansion}

Mechanically ventilated patients are often, due to lack of consciousness, unable to perform forced expiratory manoeuvres effectively. Manual hyperinflation combined with chest wall compression during expiration ("bag squeezing"; figure 7) are frequently applied in clinical practice, and improve oxygenation and lung compliance, while facilitating secretion removal [38]. Potential detrimental cardiovascular effects must be taken into consideration when applying manual hyperinflation. Its effectiveness in preventing pulmonary complications and pneumonia has been questioned, but recent data provide some evidence that physiotherapy might aid the prevention of ventilator-associated pneumonia [39].

Post-operative pulmonary complications after thoracic and abdominal surgery remain a major cause of morbidity and mortality. Prolonged hospitalisation and ICU stay may result. Early mobilisation is very effective in the

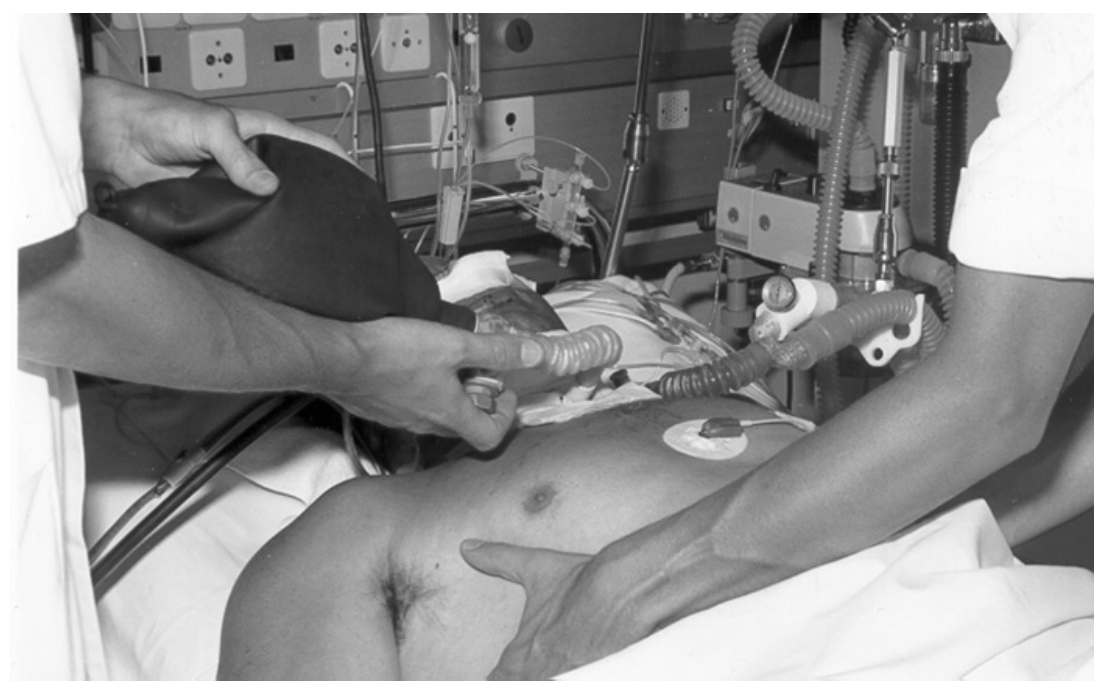

prevention of pulmonary complications. Evidence for the effectiveness of physiotherapy in preventing post-operative pulmonary complications after abdominal surgery has been provided in randomised controlled trials [40]. In addition, absence of pre-operative physiotherapy was an independent factor associated with a higher risk on post-operative pulmonary complications in patients with lung resection.

In addition to deep breathing exercises, coughing and early mobilisation, incentive spirometry is provided to reduce pulmonary complications. However, incentive spirometry has not been shown to be of additional value after major abdominal, lung and cardiac surgery [41].

\section{Conclusion}

Physiotherapy is involved in the non-medical treatment of patients with acute and chronic respiratory disease. In addition to its traditional role in the treatment of airflow obstruction and mucus retention, other aspects of respiratory disorders such as in ventilatory pump dysfunction, dyspnoea, impaired exercise performance and quality of life are also targets for physiotherapy interventions. Exercise training, peripheral and respiratory muscle training, airway clearance techniques, and breathing retraining have been shown to be effective treatments in a variety of conditions affecting the respiratory system.
Figure 7

Manual hyperinflation and chest wall compression in a ventilated patient. 


\section{Educational questions}

1. What are the important targets for treatment of patients with respiratory disease:

a) Airway obstruction, inflammation, muscle wasting, exercise intolerance and symptoms.

b) Impaired coughing, muscle weakness, exercise intolerance and dyspnoea.

c) Impaired mucus transport, impaired cough, peripheral and respiratory muscle weakness, exercise intolerance and dyspnoea.

d) Pneumonia, ARDS, COPD, neuromuscular diseases, postoperative pulmonary complications and asthma.

2. A patient with impaired mucus transport and ineffective cough/huff is best treated with:

a) Manual assisted coughing/huffing and chest percussion.

b) Treatment depends on the underlying mechanism of the impaired cough/huff.

c) Manual hyperinflation and airway suctioning in prone position.

d) PEP mask and forced expirations.

3. Muscle deconditioning is an important target for physiotherapy in:

a) Patients with neuromuscular disease.

b) Stable patients with COPD.

c) Cooperative patients with critical illness.

d) All conditions associated with reversible (expected or present) muscle weakness, independent of the cooperation of the patient.

4. High-intensity exercise training is an important treatment in:

a) Patients with mild COPD or asthma.

b) All patients with obstructive lung disease.

c) All patients with deconditioning independent of the disease severity; the exercise modality must be adjusted to the specific condition.

d) All patients with respiratory disease and deconditioning, with oxygen supplementation.

\section{Suggested further reading}

Troosters T, Casaburi R, Gosselink R, Decramer M. Pulmonary rehabilitation in chronic obstructive pulmonary disease. Am J Respir Crit Care Med 2005; 172: 19-38.

Gosselink R. Breathing techniques in patients with chronic obstructive pulmonary disease (COPD). Chron Respir Dis 2004; 1: 163-172.

Lotters F, van Tol B, Kwakkel G, Gosselink R. Effects of controlled inspiratory muscle training in patients with COPD: $a$ meta-analysis. Eur Respir J 2002; 20: 570-576.

Thomas J, Cook DJ, Brooks D. Chest physical therapy management of patients with cystic fibrosis. A meta-analysis. Am J Respir Crit Care Med 1995; 151: 846-850.

Jones AP, Rowe BH. Bronchopulmonary hygiene physical therapy for chronic obstructive pulmonary disease and bronchiectasis. Cochrane Database Syst Rev 2000; 2: CD000045.

Overend TJ, Anderson CM, Lucy SD, Bhatia C, Jonsson BI, Timmermans C. The effect of incentive spirometry on postoperative pulmonary complications: a systematic review. Chest 2001; 120: 971-978.

\section{References}

1. Pitta F, Troosters T, Spruit MA, Probst VA, Decramer M, Gosselink R. Characteristics of physical activities in daily life in chronic obstructive pulmonary disease. Am J Respir Crit Care Med 2005; 171: 972-977.

2. Herridge MS, Cheung AM, Tansey CM, et al. One-year outcomes in survivors of the acute respiratory distress syndrome. $N$ Engl J Med 2003; 348: 683-693.

3. Garcia-Aymerich J, Farrero E, Felez M, et al. Risk factors of readmission to hospital for a COPD exacerbation; a prospective study. Thorax 2003; 58: 100-105.

4. Troosters $T$, Casaburi R, Gosselink R, Decramer M. Pulmonary rehabilitation in chronic obstructive pulmonary disease. Am J Respir Crit Care Med 2005; 172: 19-38.

5. Vogiatzis I, Nanas S, Roussos C. Interval training as an alternative modality to continuous exercise in patients with COPD. Eur Respir J 2002; 20: 12-19.

6. Spruit M, Gosselink R, Troosters T, De Paepe K, Decramer M. Resistance vs endurance training in patients with COPD and peripheral muscle weakness. Eur Respir J 2002; 19: 1072-1078.

7. Neder JA, Sword D, Ward SA, Mackay E, Cochrane LM, Clark CJ. Home based neuromuscular electrical stimulation as a new rehabilitative strategy for severely disabled patients with chronic obstructive pulmonary disease (COPD). Thorax 2002; 57: 333-337.

8. Allen C, Glasziou P, Del Mar C. Bed rest: a potentially harmful treatment needing more careful evaluation. Lancet 1999; 354: 1229-1233. 
9. Griffiths RD, Palmer A, Helliwell T, Maclennan P, Macmillan RR. Effect of passive stretching on the wasting of muscle in the critically ill. Nutrition 1995; 11: 428-432.

10. Zanotti E, Felicetti G, Maini M, Fracchia C. Peripheral muscle strength training in bed-bound patients with COPD receiving mechanical ventilation: effect of electrical stimulation. Chest 2003; 124: 292-296.

11. Nava S. Rehabilitation of patients admitted to a respiratory intensive care unit. Arch Phys Med Rehabil 1998; 79: 849-854.

12. Gosselink R. Breathing techniques in patients with chronic obstructive pulmonary disease (COPD). Chron Respir Dis 2004; 1 : 163-172.

13. Renfroe KL. Effect of progressive relaxation on dyspnea and state of anxiety in patients with chronic obstructive pulmonary disease. Heart Lung 1988; 17: 408-413.

14. Bianchi R, Gigliotti F, Romagnoli I, et al. Chest wall kinematics and breathlessness during pursed-lip breathing in patients with COPD. Chest 2004; 125: 459-465.

15. Breslin EH. The pattern of respiratory muscle recruitment during pursed-lips breathing in COPD. Chest 1992; 101: 75-78.

16. Garrod R, Dallimore K, CookJ, Davies V, Quade K. An evaluation of the acute impact of pursed lips breathing on walking distance in nonspontaneous pursed lips breathing chronic obstructive pulmonary disease patients. Chron Respir Dis 2005; 2: 67-72.

17. Casciari RJ, Fairshter RD, Harrison A, Morrison JT, Blackburn C, Wilson AF. Effects of breathing retraining in patients with chronic obstructive pulmonary disease. Chest 1981; 79: 393-398.

18. Sharp JT, Druz WS, Moisan T, Foster J, Machnach W. Postural relief of dyspnea in severe chronic obstructive pulmonary disease. Am Rev Respir Dis 1980; 122: 201-211.

19. Goldman JM, Rose LS, Williams SJ, Silver JR, Denison DM. Effect of abdominal binders on breathing in tetraplegic patients. Thorax 1986; 41: 940-945.

20. Lotters F, van Tol B, Kwakkel G, Gosselink R. Effects of controlled inspiratory muscle training in patients with COPD: a metaanalysis. Eur Respir J 2002; 20: 570-576.

21. Van Houtte S, Vanlandewijck $Y$, Gosselink R. Respiratory muscle training in persons with spinal cord injury: a systematic review. Respir Med 2006; [Epub ahead of print PMID: 16626951].

22. Gosselink R, Kovacs L, Ketelaer P, Carton H, Decramer M. Respiratory muscle weakness and respiratory muscle training in severely disabled multiple sclerosis patients. Arch Phys Med Rehabil 2002; 81: 747-751.

23. Martin $A D$, Davenport $P D$, Franceschi $A C$, Harman $E$. Use of inspiratory muscle strength training to facilitate ventilator weaning: a series of 10 consecutive patients. Chest 2002; 122: 192-196.

24. Gosselink RAAM, Wagenaar RC, Sargeant AJ, Rijswijk H, Decramer MLA. Diaphragmatic breathing reduces efficiency of breathing in chronic obstructive pulmonary disease. Am J Respir Crit Care Med 2005; 151: 1136-1142.

25. Thomas J, Cook DJ, Brooks D. Chest physical therapy management of patients with cystic fibrosis. A meta-analysis. Am J Respir Crit Care Med 1995; 151: 846-850.

26. Jones $A$, Rowe BH. Bronchopulmonary hygiene physical therapy for chronic obstructive pulmonary disease and bronchiectasis. Cochrane Database Syst Rev 2000; 2: CD000045.

27. Hasani A, Pavia D, Agnew JE, Clarke SW. Regional mucus transport following unproductive cough and forced expiration technique in patients with airways obstruction. Chest 1994; 105: 1420-1425.

28. Sivasothy P, Brown L, Smith IE, Shneerson JM. Effect of manually assisted cough and mechanical insufflation on cough flow of normal subjects, patients with chronic obstructive pulmonary disease (COPD), and patients with respiratory muscle weakness. Thorax 2001; 56: 438-444.

29. Bach JR. Mechanical insufflation-exsufflation. Comparison with peak expiratory flows with manually assisted and unassisted coughing techniques. Chest 1993; 104: 1553-1562.

30. Wolff RK, Dolovich MB, Obminski G, Newhouse MT. Effects of exercise and eucapnic hyperventilation on bronchial clearance in man. J Appl Physiol 1977; 43: 46-50.

31. Oldenburg FA, Dolovich MB, Montgomery JM, Newhouse MT. Effects of postural drainage, exercise and cough on mucus clearance in chronic bronchitis. Am Rev Respir Dis 1979; 120: 739-745.

32. Baldwin DR, Hill AL, Peckham DG, Knox AJ. Effect of addition of exercise to chest physiotherapy on sputum expectoration and lung function in adults with cystic fibrosis. Respir Med 1994; 88: 49-53.

33. Rossman CM, Waldes R, Sampson D, Newhouse MT. Effect of chest physiotherapy on the removal of mucus in patients with cystic fibrosis. Am Rev Respir Dis 1998; 126: 131-135.

34. Sutton PP, Parker RA, Webber BA, et al. Assessment of the forced expiration technique, postural drainage and directed coughing in chest physiotherapy. Eur J Respir Dis 1983; 64: 62-68.

35. van der Schans CP, Piers DA, Postma DS. Effect of manual percussion on tracheobronchial clearance in patients with chronic airflow obstruction and excessive tracheobronchial secretion. Thorax 1986; 41: 448-452.

36. Falk M, Kelstrup M, Andersen JB, et al. Improving the ketchup bottle method with positive expiratory pressure (PEP), in cystic fibrosis. EurJ Respir Dis 1984; 65: 423-432.

37. McIlwaine PM, Wong LT, Peacock D, Davidson AGF. Long-term comparative trial of convential postural drainage and percussion versus positive expiratory pressure therapy in the treatment of cystic fibrosis. J Pediatr 1997; 131: 570-574.

38. Hodgson C, Denehy L, Ntoumenopoulos G, Santamaria J, Carroll S. An investigation of the early effects of manual lung hyperinflation in critically ill patients. Anaesth Intensive Care 2000; 28: 255-261.

39. Ntoumenopoulos G, Presneill JJ, McElholum M, Cade JF. Chest physiotherapy for the prevention of ventilator-associated pneumonia. Intensive Care Med 2002; 28: 850-856.

40. Fagevik Olsen M, Hahn I, Nordgren S, Lonroth H, Lundholm K. Randomized controlled trial of prophylactic chest physiotherapy in major abdominal surgery. Br J Surg 1997; 84: 1535-1538.

41. Overend TJ, Anderson CM, LuCy SD, Bhatia C, Jonsson BI, Timmermans C. The effect of incentive spirometry on postoperative pulmonary complications: a systematic review. Chest 2001; 120: 971-978.

Suggested answers
1. c
2. b
3. d
4. c

